\title{
ERRATUM
}

\section{Erratum to: Sorption behaviour of torrefied wood and charcoal determined by dynamic vapour sorption}

\author{
Maija Kymäläinen $^{1}$ Lauri Rautkari ${ }^{2}$ Callum A. S. Hill ${ }^{3,4}$
}

Published online: 29 September 2015

(C) Springer Science+Business Media New York 2015

Erratum to: J Mater Sci (2015) 50:7673-7680

DOI 10.1007/s10853-015-9332-2

There were errors in Fig. 4 of the published version. The corrected Fig. 4 is shown below.
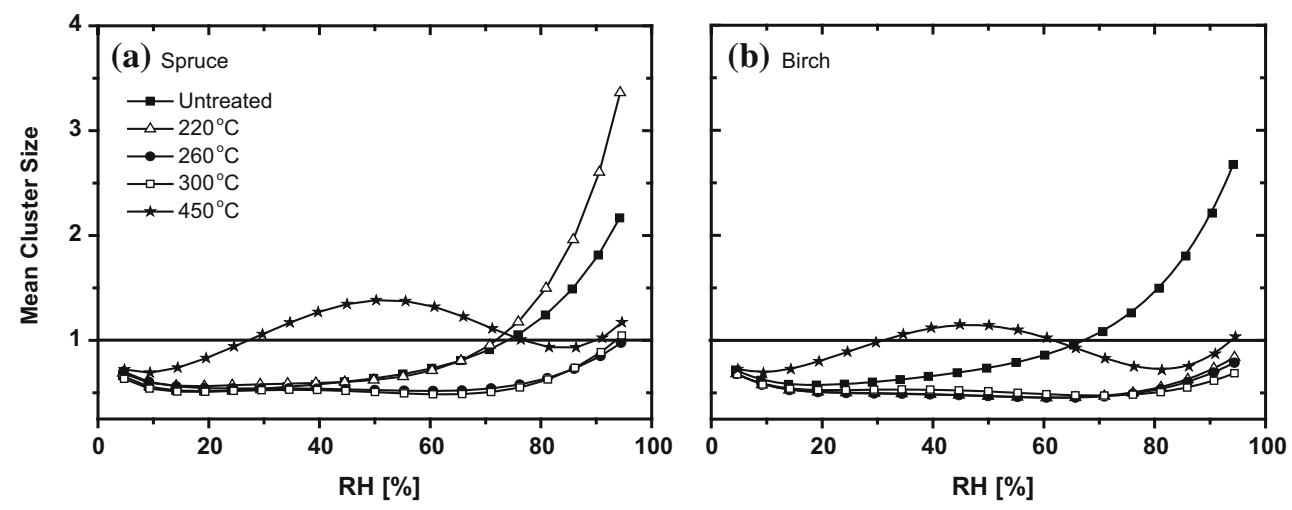

Fig. 4 Clustering of sorbed water molecules in birch and spruce determined using the Zimm-Lundberg approach

The online version of the original article can be found under doi:10.1007/s10853-015-9332-2.

Maija Kymäläinen

maija.kymalainen@helsinki.fi

1 Department of Forest Sciences, University of Helsinki, P.O. Box 27, 00014 Helsinki, Finland

2 Department of Forest Products Technology, School of Chemical Technology, Aalto University, P.O. Box 16300, 00076 Aalto, Finland

3 Norwegian Forest and Landscape Institute, PO Box 115, 1431 Ås, Norway

4 Department of Architecture and Civil Engineering, University of Bath, Claverton Down, Bath BA2 7AY, UK 